\title{
Quality of supplementary LED lighting effects on growth and photosynthesis of two different Lactuca recombinant inbred lines (RILs) grown in a tropical greenhouse
}

\author{
T.W. CHOONG, J. HE ${ }^{+}$, L. QIN, and S.K. LEE \\ Natural Sciences and Science Education Academic Group, National Institute of Education, Nanyang Technological \\ University, 1 Nanyang Walk, Singapore 637 616, Singapore
}

\begin{abstract}
LED lamps with various combinations of red (R) and blue (B) wavelengths were used to supplement sunlight for the growth of a heat-resistant (HR) and heat-sensitive (HS) recombinant inbred lines (RIL) of lettuce. The RB-LED ratios were 100R:0B (0B), 92R:8B (8B), 84R:16B (16B), and 76R:24B (24B) with an equal PPFD of $100 \mu \mathrm{mol} \mathrm{m}^{-2} \mathrm{~s}^{-1}$. The greatest leaf expansion rates were observed at $8 \mathrm{~B}$ for both genotypes. All HR-RILs had similar values of growth parameters and specific leaf area (SLA). However, higher values of growth parameters were observed in HS-RIL with 0B, 8B, and 16B than that under 24B and sunlight. Furthermore, HS-RIL had higher SLA under 0B compared to other conditions. Photosynthetic light-use efficiency and maximal oxygen evolution rate were the lowest under $8 \mathrm{~B}$ for both genotypes. The quality of LED lighting, if provided, seemed to implicate genotype dependence, probably as a result of their different sensitivities to heat stress.
\end{abstract}

Additional key words: electron transport rate; leaf expansion; light- and $\mathrm{CO}_{2}$-saturated net photosynthetic rate; photochemical and nonphotochemical quenching; pigment; stomatal density.

\section{Introduction}

Located near the Equator, warm temperatures throughout the year are typical of a tropical environment that allow for growth and production of vegetables all year round. However, in Singapore, plants are normally exposed to a few clear sunny days, followed by days of cloudy weather (He et al. 1996). In recent years, Singapore has been more frequently experiencing increasingly unpredictable environmental conditions of cloudy and hazy weather (Nobre et al. 2016). Since 1982, Singapore has been experiencing hazy weather almost annually due to large-scale forest fires that occur in the neighbouring countries. This is a concern as the resulting lowered light intensity compromised the productivity of crop plants (Jones 2006), resulting in longer growing periods. For instance, He et al. (2011a) reported that in Singapore, when lettuce plants were grown under low light during the haze episodes or under simulated haze conditions in the greenhouse, lower photosynthetic rate and stomatal conductance $\left(g_{s}\right)$ were measured. Furthermore, plant productivity was lower with an increase in a nitrate concentration when compared to plants grown under higher light. Similar results were obtained with Brassica alboglabra (Chinese broccoli) (He et al. 2015a). In order to circumvent the problem of insufficient sunlight for cultivation of vegetable crops, this research implements the use of light-emitting diode (LED) light to supplement low sunlight intensity, whilst optimizing the use of existing natural irradiance.

With their high photoelectric conversion efficiencies, low thermal output and narrow band spectra (Yeh and Chung 2009), LED lamps have recently been preferred for use in crop production. As such, LEDs, which have the ability to enhance plant growth and photomorphogenesis, can be used to irradiate plants (Yorio et al. 2001, Watanabe 2011, Goto 2012, He et al. 2015b, Hernández and Kubota

Received 9 June 2017, accepted 7 February 2018, published as online-first 21 June 2018.

${ }^{+}$Corresponding author; phone: 65-67903817; fax: 65-68969432, e-mail: jie.he@nie.edu.sg

Abbreviations: B - blue; Car - carotenoids; Chl - chlorophyll; DM - dry mass; ETR - electron transport rate; FM - fresh mass; HR heat-resistant; $\mathrm{HS}$ - heat-sensitive; LED - light emitting diode; NPQ - nonphotochemical quenching; $P_{\mathrm{Nmax}}-$ light- and $\mathrm{CO}_{2}$-saturated net photosynthetic rate; $\mathrm{q}_{\mathrm{p}}$ - photochemical quenching; R - red; RIL - recombinant inbred lines; SD - stomatal density; SL - sunlight; SLA - specific leaf area.

Acknowledgement: This project was funded by Singapore Millennium Foundation, Singapore (SMF-Farming System), and Monetary Academic Resources for Research, Nanyang Technological University, Singapore. We thank the Michelmore Lab at the UC Davis Genome Centre for providing us with the RIL seeds. 
2016, Wang et al. 2016). Sager and McFarlane (1997) have previously used McCree's curve to explain how the use of $R$ wavelengths (600-700 nm), being so close to the absorption peak of chlorophyll (Chl), can most efficiently power photosynthesis as they are maximally absorbed by plant pigments and phytochromes (Muneer et al. 2014). In comparison, $\mathrm{B}$ wavelengths of light perform photomorphogenic roles, such as phototropism (Blaauw and Blaauw-Jansen 1970), affecting water relations and carbon dioxide exchange, stem elongation (Cosgrove 1981), and stomatal control (Schwartz and Zeiger 1984, Hernández and Kubota 2016, Wang et al. 2016). Thus, using peak wavelengths of $B(460 \mathrm{~nm})$ and $\mathrm{R}(660 \mathrm{~nm})$ quality, matching the active spectra of the plant's photoreaction system, Johkan et al. (2010) successfully cultivated red leaf lettuce. Using 50R:50B LED irradiation, with PPFD at $100 \mu \mathrm{mol} \mathrm{m}^{-2} \mathrm{~s}^{-1}$, the leaf shape and colour of the lettuce plants were similar to those grown under fluorescent light. Studies have reported that higher plant fresh mass (FMs) were obtained when grown with B light (Yorio et al. 2001, Matsuda et al. 2008). Bula et al. (1991) and Hoenecke et al. (1992) also found that insufficient intensity of B wavelengths of light resulted in elongation of leaf stems and internodes.

It was also reported that the optimal combination of $\mathrm{R}$ and $\mathrm{B}$ light is species-dependent. For instance, $\mathrm{R} / \mathrm{B}$ light ratios were $7 / 3$ in strawberry plantlet (Nhut et al. 2003) and $1 / 3$ in rapeseed plantlets in vitro (Li et al. 2013),

\section{Materials and methods}

Plant materials and culture methods: The Lactuca RILs were obtained from crossing L. sativa L. 'Salinas' and L. serriola accession UC96US23 (Argyris et al. 2005). The seeds of previously identified HR- and HS-RILs (Choong et al. 2013) were germinated on moist filter paper in a petri dish, in the laboratory. Insertion of seedlings into polyurethane cubes, soaked in water, was carried out five days after germination. These seedlings were left to acclimatize to ambient tropical greenhouse conditions for $7 \mathrm{~d}$ before being transplanted into the aeroponic system (Lee 1993). The shoots of plants were exposed to $100 \%$ prevailing irradiances at a maximum PPFD of $800 \mu \mathrm{mol}$ $\mathrm{m}^{-2} \mathrm{~s}^{-1}$ on sunny days, with fluctuating ambient temperatures of $28-38^{\circ} \mathrm{C}$ and relative humidity of $65-95 \%$. The roots were misted with full strength Netherlands Standard Composition (Douglas 1985) nutrient solution (EC $2.2 \mathrm{mS}, \mathrm{pH} 6.5$ ), for $30 \mathrm{~s}$ between $5 \mathrm{~min}$ intervals and rootzone temperatures were kept at $25 \pm 3^{\circ} \mathrm{C}$ for the entire period of plant growth.

Supplementary LED-irradiance treatments: Plants were either grown under only natural sunlight (SL) or supplemented with one of the four RB-LED combinations for a continuous 10-h photoperiod (i.e., 08:00-18:00 h) at mean PPFD of $100 \mu \mathrm{mol} \mathrm{m} \mathrm{m}^{-2} \mathrm{~s}^{-1}$ from the day of transplantation. The RB-LED lighting combinations were respectively. However, it was 9/1 for Arabidopsis (Ooi et al. 2016), cucumber seedlings (Hernández and Kubota 2016), lettuce (Yorio et al. 2001, Stutte et al. 2009), and spinach (Yorio et al. 2001). As such, appropriate spectral quality needs to be identified for optimal plant growth as the optimal wavelengths seemed to be crop-specific (Hanyu and Shoji 2002, Massa et al. 2008, He et al. 2015b).

RB-LED lamps have a great potential as a light source to drive photosynthesis. Since different vegetable crops respond distinctly to RB light combinations (Yorio et al. 2001, Nhut et al. 2003, Stutte et al. 2009, Li et al. 2013, Hernández and Kubota 2016, Wang et al. 2016), this research studied this effect on two different thermotolerant Lactuca RILs previously selected (Choong et al. 2013). Using HR-RIL and HS-RIL, our team has reported that shoot and root FM of HR-RIL were significantly higher than that of HS RILs that were grown in the tropical greenhouse under ambient conditions due to their lower photoinhibition of PSII reaction center during midday (He et al. 2013). Recently, we have confirmed further that HRRIL grown in the tropical greenhouse showed lesser photoinhibition as compared to HS-RIL (Lai and He 2016). Thus, we hypothesised that the two different genotypes, HR-RIL and HS-RIL, may exhibit different responses to supplemental light quality when they were grown in the tropical greenhouse. Here we reported results of the influence of supplemental light quality on two different thermotolerant lettuce RIL lines.

100R:0B (0B)，92R:8B (8B)，84R:16B (16B), and 76R:24B (24B). The spectral flux density of the various light treatments is shown in Fig. 1.

Growth parameters: Three or more plants of each genotype were harvested 28 days after transplant. Plant height was measured, leaf numbers were counted, and shoot and

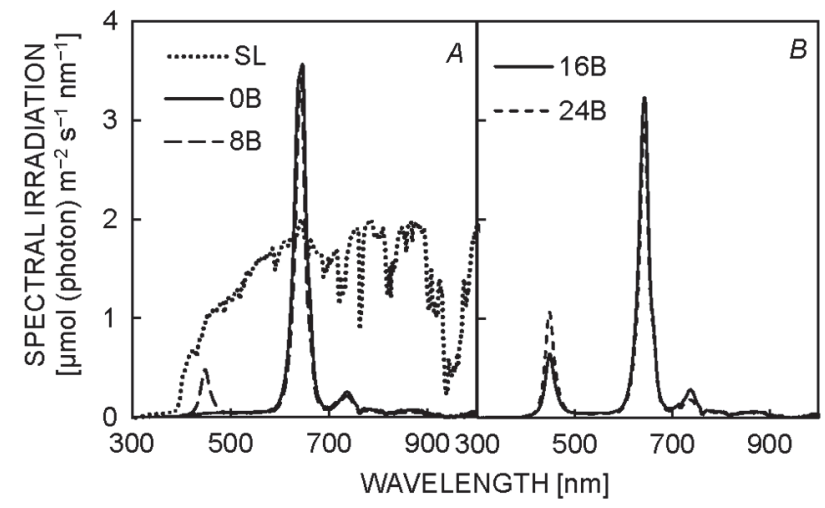

Fig. 1. Light spectral measurements with a spectroradiometer (PS300, Apogee Instruments, USA). Lettuce plants were grown under natural sunlight (SL) and four different supplementary RBLED light combinations (0B, 8B, 16B, 24B), with PPFD of $100 \mu \mathrm{mol} \mathrm{m}^{-2} \mathrm{~s}^{-1}$. $A$ : $\mathrm{SL}, 0 \mathrm{~B}$, and $8 \mathrm{~B} ; B: 16 \mathrm{~B}$ and $24 \mathrm{~B}$. 
root FM were weighed after harvest. The shoot/root ratios were calculated using their FMs. Images of all leaves were captured and total leaf area was analyzed using WinDIAS 3 image analysis system (Delta-T Device, UK). SLA was calculated by dividing the area of ten one-cm-diameter leaf discs with their dry mass, after drying for $5 \mathrm{~d}$ at $65^{\circ} \mathrm{C}$ in an oven.

Leaf expansion: Young leaves were selected from at least four plants of each genotype and treatments. The images of the selected leaves were captured for four consecutive days, starting from $11 \mathrm{~d}$ after transplantation. Their areas were then analyzed using the WinDIAS 3 software (DeltaT Device, Led, UK) (Tay et al. 2015).

Stomatal density (SD): An epidermal impression was obtained by coating the abaxial leaf surface with clear nail varnish. The dried nail varnish was peeled off and adhered to a microscope slide using clear sticky tape. The peel was viewed under the microscope at $\times 400$ magnification. Three different fields of view were counted per peel and at least two peels were obtained per genotype and light treatment. The diameter of the field of view was measured using a ruler and the area calculated. SD was then calculated as the number of stomata per square millimeter.

Light- and $\mathrm{CO}_{2}$-saturated net photosynthetic rate $\left(\boldsymbol{P}_{\text {Nmax }}\right)$ : Newly mature lettuce leaves were obtained, using an oxygen electrode system (Model LD2, Hansatech Ltd., King Lynn, England) at $25^{\circ} \mathrm{C}$ (Ball et al. 1987), $24 \mathrm{~d}$ after transplantation. The leaves were harvested at about 09:00 h local time (i.e., within $2 \mathrm{~h}$ after sunrise) from at least three different plants per genotype and light treat-

\section{Results}

Leaf expansion: HR-RIL demonstrated the fastest leaf expansion rate under $8 \mathrm{~B}$, followed by $16 \mathrm{~B}$ and $24 \mathrm{~B}$, LEDlighting treatment (Fig. 2A). Leaf expansion under SL and $0 \mathrm{~B}$ were similar but distinctly lower (Fig. $2 A$ ). The highest leaf expansion rate in HS-RIL was observed under $8 \mathrm{~B}$ followed by $16 \mathrm{~B}$. HS-RIL had similar lower leaf expansion rates under SL, 0B, and 24B conditions (Fig. 2B). ment. A $10-\mathrm{cm}^{2}$ leaf disc was cut from the leaf and placed at a chamber containing saturated $\mathrm{CO}_{2}\left(1 \% \mathrm{CO}_{2}\right.$ from a $1 \mathrm{~mol} \mathrm{~L}^{-1}$ carbohydrate/bicarbonate buffer, $\mathrm{pH}$ 9). Photosynthetic $\mathrm{O}_{2}$ evolution rates were measured under PPFDs of 1,$000 ; 1,200 ; 1,500 ;$ and $1,900 \mu \mathrm{mol} \mathrm{m}^{-2} \mathrm{~s}^{-1}$. It was found that a PPFD $1,500 \mu \mathrm{mol} \mathrm{m} \mathrm{m}^{-2} \mathrm{~s}^{-1}$ saturated both HRRIL and HS-RIL leaf photosynthesis. The leaf disc was illuminated with PPFD of $1,500 \mu \mathrm{mol} \mathrm{m} \mathrm{m}^{-2} \mathrm{~s}^{-1}$ till a steady state of photosynthetic $\mathrm{O}_{2}$ evolution rate was obtained.

Photosynthetic pigments: Four one-cm-diameter leaf discs were obtained from newly expanded leaves of three different plants. The leaf discs were left for $48 \mathrm{~h}$ in the dark, at $4^{\circ} \mathrm{C}$, in $1.5 \mathrm{ml} \mathrm{N}, \mathrm{N}$-dimethylformamide. Absorption of four replicates was read at 480, 647, and $664 \mathrm{~nm}$, using a spectrophotometer ( $U V-2550$, Shimadzu, Japan) and Chl $a$, $\mathrm{Chl} b$, total Chl, and carotenoids (Car) concentrations were calculated using the Wellburn (1994) method.

Photochemical light-use efficiency: Leaves were harvested at 09:00 $\mathrm{h}$ for $\mathrm{Chl}$ fluorescence analysis, where photochemical quenching $\left(\mathrm{q}_{\mathrm{p}}\right)$, nonphotochemical quenching (NPQ), and electron transport rate (ETR) of four detached newly expanded leaves from four different plants were measured at $25^{\circ} \mathrm{C}$ in the laboratory, using the Imaging-PAM Chl fluorometer (Walz, Effeltrich, Germany) (He et al. 2011b).

Statistical analysis: A mixed-model nested analysis of variance (ANOVA) was performed using SPSS (Version 20, 2011) to test for significant effects of variation between genotypes and their response to light treatments, using posthoc Tukey's pairwise test, with significance at $\alpha=0.05$.

Plant height, leaf number and productivity: In terms of other productivity parameters, such as plant height (Fig. 3A), leaf number (Fig. 3C), shoot FM (Fig. 3E), and root FM (Fig. $3 G$ ), all values were quite similar across the different RB-LED combinations for HR-RIL. On the other hand, plant height (Fig. 3B), shoot and root FMs (Fig. $3 F, H$ ) were lower under $\mathrm{SL}$ and $24 \mathrm{~B}$ than the rest of the

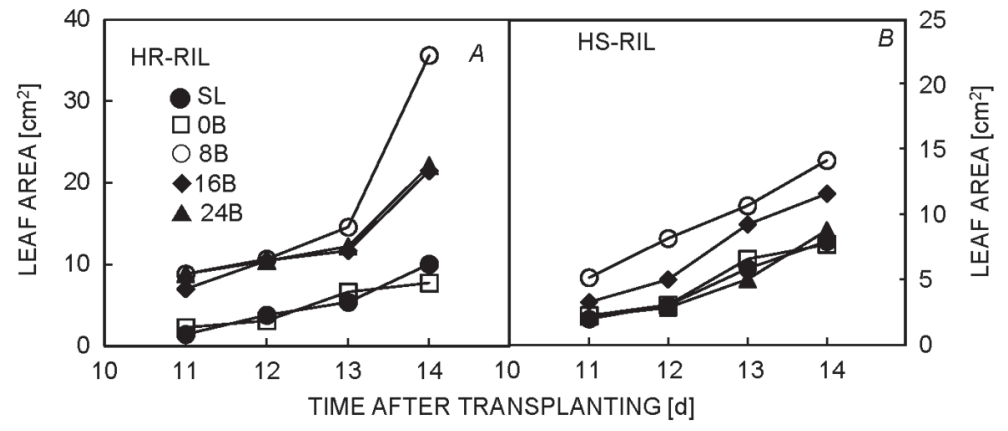

Fig. 2. Leaf expansion of HR-RIL $(A)$ and HS-RIL $(B)$. Lettuce plants were grown under SL and four different supplementary RB-LED light combinations (0B, 8B, 16B, 24B), with PPFD of $100 \mu \mathrm{mol} \mathrm{m}^{-2} \mathrm{~s}^{-1}$. Each value is the mean of at least three different plants $(n \geq 3)$. 


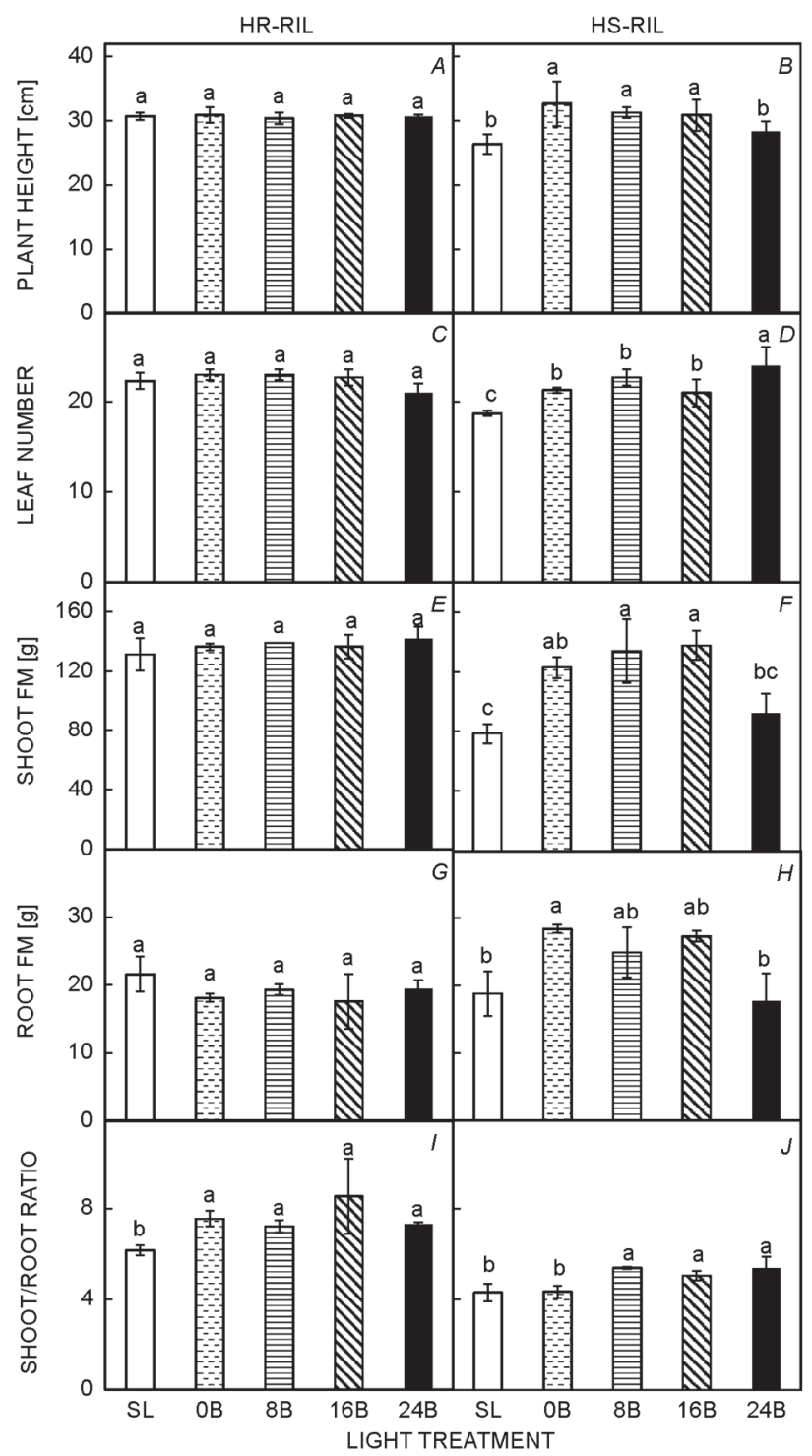

Fig. 3. Plant height $(A, B)$, leaf number $(C, D)$, shoot FM $(E, F)$. root FM $(G, H)$ shoot/root ratio $(I, J)$ of HR-RIL $(A, C, E, G, I)$ and HS-RIL $(B, D, F, H, J)$ grown under SL and four different RB-LED light treatments $(0 \mathrm{~B}, 8 \mathrm{~B}, 16 \mathrm{~B}, 24 \mathrm{~B})$, with PPFD of $100 \mu \mathrm{mol}$ $\mathrm{m}^{-2} \mathrm{~s}^{-1}$. Parameters were measured $28 \mathrm{~d}$ after transplantation. Each value is the mean of at least three different plants $(n \geq 3)$. Means with different letters are statistically different $(p<0.05$; $n \geq 3$ ) as determined by Tukey's multiple comparison test.

RB-LED-light treatments for HS-RIL. HS-RIL had the lowest leaf number when grown under SL and the greatest leaf number under 24B-light treatment (Fig. 3D). The shoot/root ratio of HR-RIL was lower under SL compared to all other RB-LED treatment. However, there was no significant difference in shoot/root ratios for HR-RIL between the different RB-LED treatments (Fig. 3I). Shoot/root ratios were similarly lower for HS-RIL under $\mathrm{SL}$ and $\mathrm{OB}$ but much higher under $8 \mathrm{~B}, 16 \mathrm{~B}$, and $24 \mathrm{~B}$ (Fig. 3J).

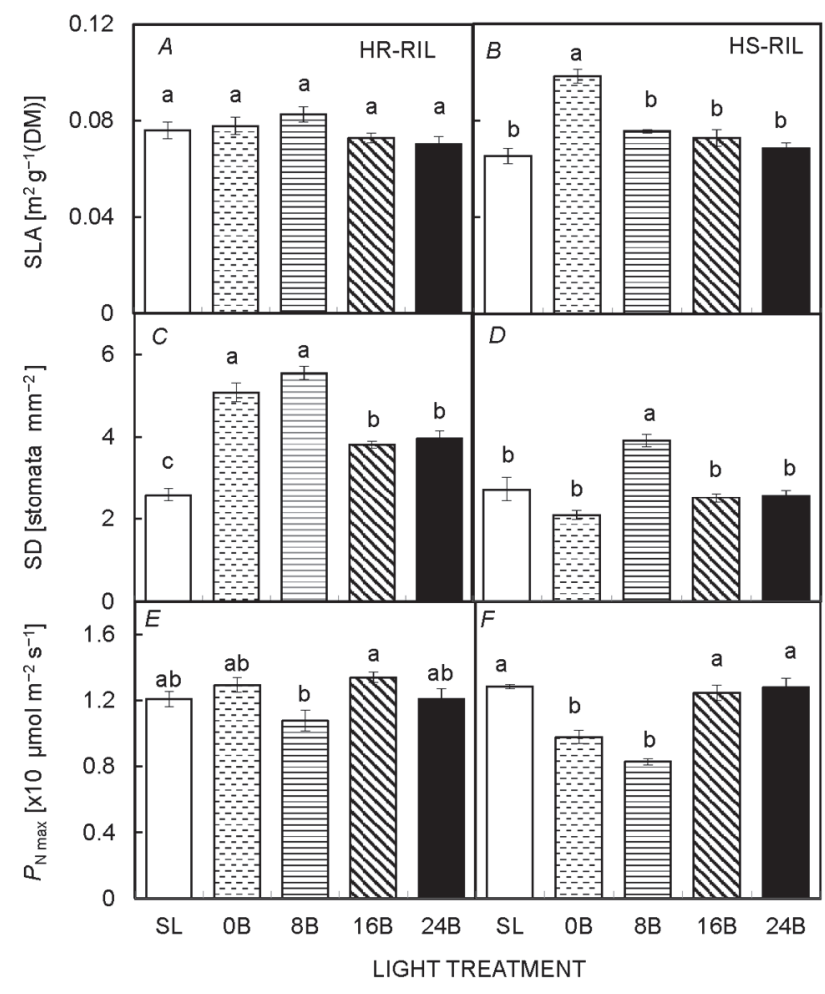

Fig. 4. SLA $(A, B), \operatorname{SD}(C, D)$, and $P_{\mathrm{Nmax}}(E, F)$ of HR-RIL $(A, C, E)$ and HS-RIL $(B, D, F)$ grown under natural SL and four different supplementary RB-LED light combinations (0B, 8B, 16B, 24B), with PPFD of $100 \mu \mathrm{mol} \mathrm{m} \mathrm{m}^{-2} \mathrm{~s}^{-1}$. Measurements were made 28 days after transplant. Each bar graph is the mean of at least three different plants $(n \geq 3)$. Vertical bars represent the standard errors. Means with different letters are statistically different $(p<0.05 ; n \geq 3)$ as determined by Tukey's multiple comparison test.

SLA, SD and $\boldsymbol{P}_{\text {Nmax }}$ : SLA values (Fig. $4 A$ ) were highly similar regardless of light treatments for HR-RIL. However, for HS-RIL, SLA was distinctly higher under 0B light (Fig. 4B). Significantly greater SD was observed under $0 \mathrm{~B}$ and $8 \mathrm{~B}$ light treatments for HR-RIL (Fig. 4C) whereas SD for HS-RIL was only significantly higher under $8 \mathrm{~B}$ light treatment (Fig. 4D). The significantly highest $P_{\text {Nmax }}$ was observed under $16 \mathrm{~B}$ for HR-RIL (Fig. $4 E$ ), whereas they were significantly higher for all light treatments of SL, 16B and 24B for HS-RIL (Fig. 4F).

Photosynthetic pigments, $\mathrm{q}_{\mathrm{p}}$, NPQ and ETR: Compared to plants grown under SL, even though concentrations of both $\mathrm{Chl} a$ and $\mathrm{Chl} b$ (data not shown) and total Chl (Fig. $5 C$ ) were greater at $0 \mathrm{~B}, 8 \mathrm{~B}, 16 \mathrm{~B}$ and $24 \mathrm{~B}$, for HRRIL, the Chl $a / b$ ratios were similar across all light treatments (Fig. 5A). For HS-RIL, Chl $a$ and Chl $b$ concentrations (data not shown) and total Chl were the lowest under SL, but the Chl $a / b$ ratio was significantly the greatest one (Fig. 5B). Though total Chl contents was 


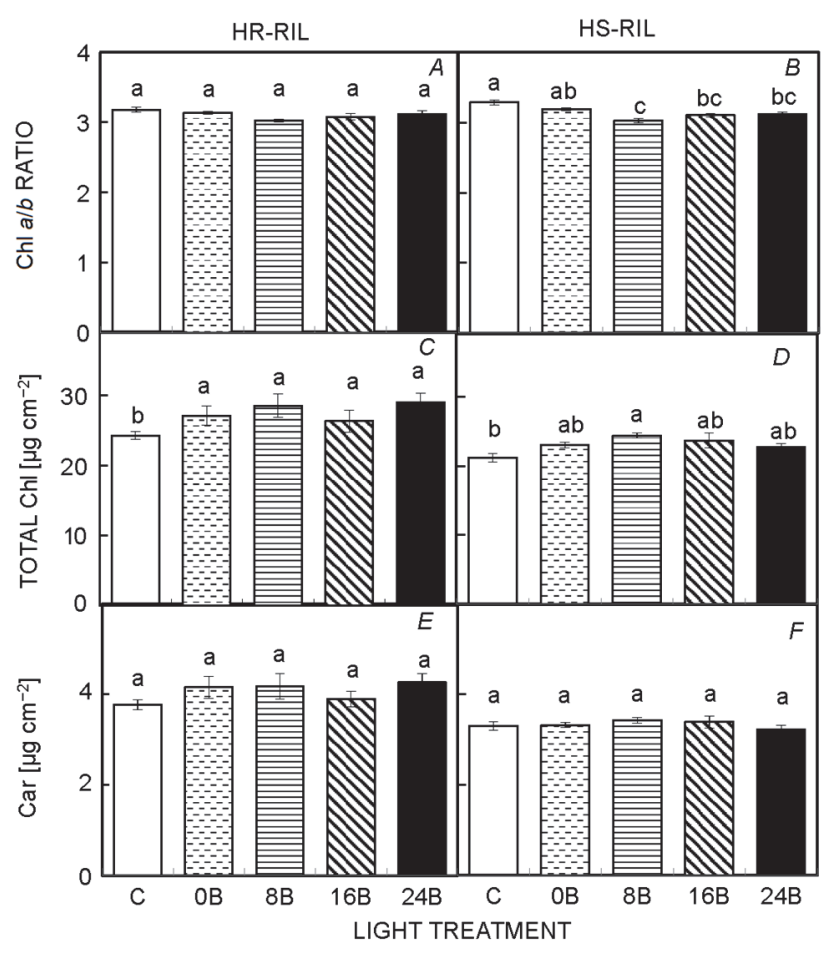

Discussion

Over the past two decades, many studies have been carried out indoors to study application of LED lighting on vegetable production. It is well-known that light quality affects plant morphology and growth (Goins et al. 1997, Yorio et al. 2001, Matsuda et al. 2008, Cope and Bugbee 2013, Chang et al. 2016, Wang et al. 2016). Due to the regular cloudiness and several episodes of haze annually, most vegetables in Singapore are subjected to low greenhouse ambient light (He et al. 2011, 2015a). However, very little information is available on the supplementation of LED lighting to prevailing solar radiation in the tropical greenhouse for enhanced productivity of vegetable crops. This study used HR-RIL and HS-RIL of lettuce, which have different susceptibility to heat stress (Lai and He 2016) and photoinhibition (He et al. 2013) to study the impact of supplemental red- and blue-LED lighting on growth and photosynthesis in a tropical greenhouse in Singapore.

Studies have shown that the presence of B-LED lighting, in addition to R-LED lighting allows better and faster growth of plants (Yorio et al. 2001, Matsuda et al. 2008, Hogewoning et al. 2010, Darko et al. 2014, Muneer et al. 2014, He et al. 2015b, Wang et al. 2016, He et al. 2017). It can be observed that leaf expansion occurred at a distinctly higher rate of growth under $8 \mathrm{~B}$ for both HR-RIL and HS-RIL (Fig. 2). This observation was also reported by Johkan et al. (2010) in red leaf lettuce, where larger leaf area was obtained at harvest under RB light quality. Supplementing only $\mathrm{R}$ light was ineffective as the leaf expansion rates for both genotypes were only equivalent to
Fig. 5. Chl $a / b$ ratio $(A, B)$, total Chl content $(C, D)$, and Car content $(E, F)$ of HR-RIL $(A, C, E)$ and HS-RIL $(B, D, F)$ grown under natural SL and four different supplementary RB-LED light combinations (0B, 8B, 16B, 24B) ), with PPFD of $100 \mu \mathrm{mol}$ $\mathrm{m}^{-2} \mathrm{~s}^{-1}$. Each bar graph is the mean of at least three different plants $(n \geq 3)$. Vertical bars represent the standard errors. Means with different letters are statistically different $(p<0.05 ; n \geq 3)$ as determined by Tukey's multiple comparison test.

significantly lower under SL (Fig. 5D), for HS-RIL, the Car content was not significantly different under all light treatment (Fig. 5F). For HR-RIL, all plants also had the similar Car content (Fig. 5E). Fig. 6 shows the values of $\mathrm{q}_{\mathrm{p}}$, NPQ, and ETR measured under a PPFD of $605 \mu \mathrm{mol}$ $\mathrm{m}^{-2} \mathrm{~s}^{-1}$. The highest $\mathrm{q}_{\mathrm{p}}$ and ETR were found at 24B-light treatment for both genotypes (Fig. 6A,B,E,F). The significantly lowest NPQ was observed at 24B-light treatment for both genotypes (Fig. 6C,D). Plants grown under $0 \mathrm{~B}$ and $8 \mathrm{~B}$ had lower $\mathrm{q}_{\mathrm{p}}$ (Fig. $6 A, B$ ) and ETR (Fig. 6E,F) compared to other light treatments in both genotypes.

that of plants growing under natural SL (Fig. 2). Evidence of crop specificity to quality of supplementary LED illumination can also be observed where leaf expansion at 24B-LED light treatment was similar to that at $16 \mathrm{~B}$, in HR-RIL (Fig. 2A), but in HS-RIL, they were more closely associated to SL and $0 \mathrm{~B}$ instead (Fig. 2B). As such, HS-RIL exhibited higher sensitivity towards higher amounts of B light than HR-RIL. On the other hand, the leaf growth rate in HS-RIL (Figs. $2 B$ ) was much lower than that of HR-RIL. Similar results were also found in other HR-RIL and HS-RIL. For example, we found that optimal percentages of B light were different for different green and red leaf lettuce (Lactuca sativa 2326 and 2328) that have different sensitivities to heat stress and photoinhibition (unpublished data). Although there were some variations in the results due to the variations in greenhouse conditions and the optimal combination of R- and B-LED was species-dependent (Yorio et al. 2001, Nhut et al. 2003, Li et al. 2013, Hernández and Kubota 2016, Ooi et al. 2016), most experiments showed that supplemental LED lighting can increase crop productivity in periods of low light under any combination of R- and B-LED with B-LED fractions from 8 to $30 \%$.

No significant differences between different light treatments could be detected amongst all growth traits for HR-RIL, suggesting that the intensity (i.e., quantity) per se of supplementary RB lighting may impact the HR-RIL to a noteworthy extent (Fig. 3). HR-RIL had larger leaf area under $8 \mathrm{~B}$ followed by $16 \mathrm{~B}$ and $24 \mathrm{~B}$ compared to SL and 0B (Fig. 2A). The PPFD of $100 \mu \mathrm{mol} \mathrm{m} \mathrm{m}^{-2} \mathrm{~s}^{-1}$ may be 


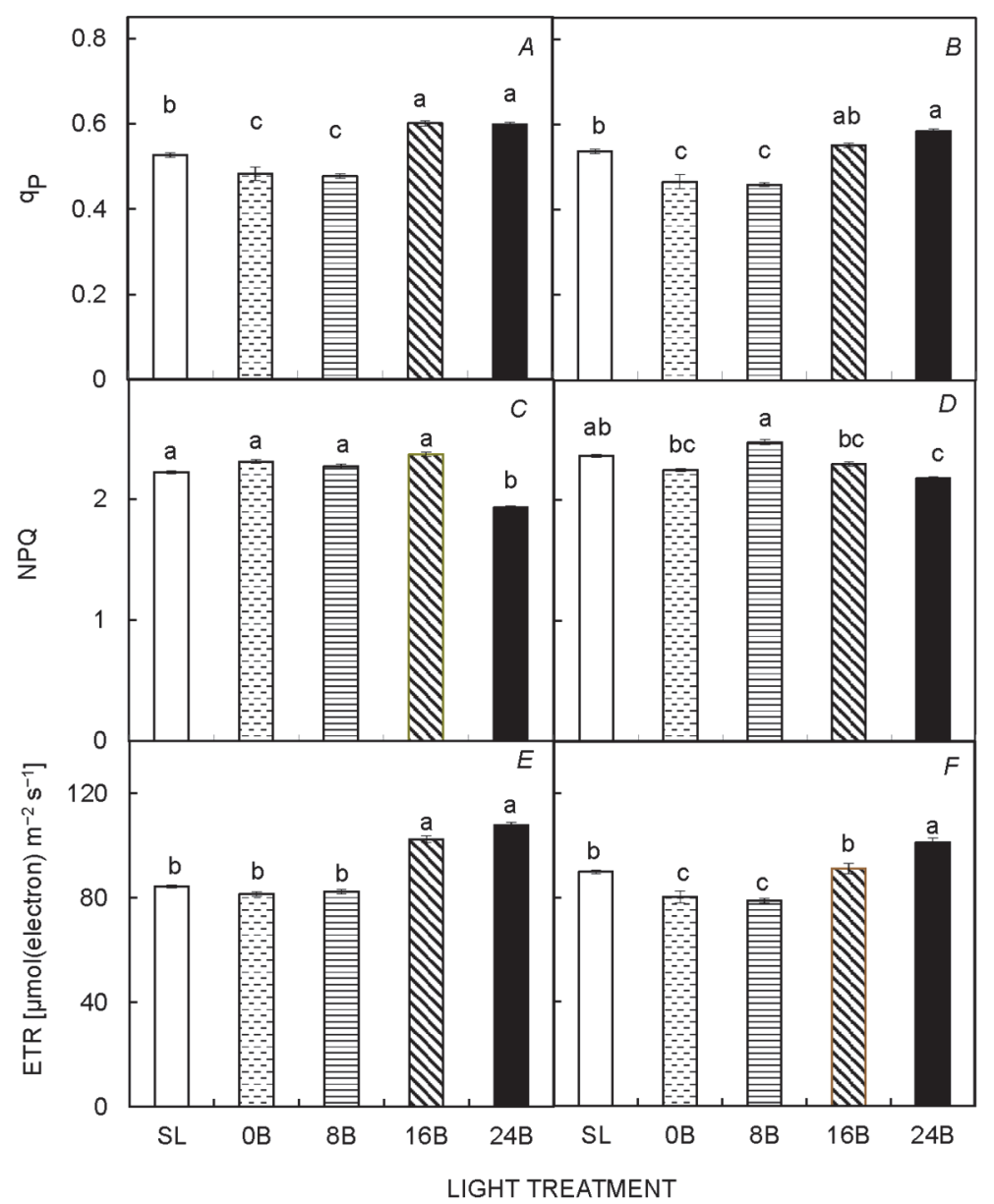

Fig. 6. qp $(A, B)$, NPQ $(C, D)$, and ETR $(E, F)$ of HRRIL $(A, C, E)$ and HS-RIL $(B, D, F)$ grown under natural SL and four different supplementary RBLED light combinations (0B, 8B, 16B, 24B) ), with PPFD of $100 \mu \mathrm{mol} \mathrm{m}{ }^{-2} \mathrm{~s}^{-1}$. All measurements were made under a PPFD of $605 \mu \mathrm{mol} \mathrm{m} \mathrm{m}^{-2} \mathrm{~s}^{-1}$. Each bar graph is the mean of at least three different plants $(n \geq 3)$. Vertical bars represent the standard errors. Means with different letters are statistically different $(p<0.05 ; n \geq 3)$ as determined by Tukey's multiple comparison test. too low to cause any significant changes for HR-RIL. Christophe et al. (2006) reported that leaf appearance rate and petiole elongation of white clover (Trifolium repens L.) were strongly controlled not only by the changes of blue light portion but also its intensity. Larger leaf area normally captures more light to promote growth (Gifford et al. 1984, Koester et al. 2014). However, all HR-RIL plants had similar shoot FM (Fig. 3E) and leaf thickness measured by SLA (Fig. 4A) regardless of light treatments. In studies with Arabidopsis, the relationship between leaf area and plant biomass was found to be non-linear and variable depending on carbon partitioning (Weraduwage et al. 2015). The relationship between leaf area growth and growth of lettuce in terms of total FM may depend on how newly fixed carbon is partitioned among new leaf area, leaf mass, stem mass and root mass. In the present study, we did not separate the leaf mass and stem mass. Those plants with lower leaf growth could channel more biomass to their stem. The shoot/root ratios (Fig. 3I) of HR-RIL, were the lowest under SL and greatest under 16B. However, there was no significant difference in shoot FMs amongst the light treatments. The outstanding shoot/root ratio at 16B light treatment could be an indicator of the optimal $\mathrm{R} / \mathrm{B}$ ratio for supplementary light treatment for HR-RIL.
Another crucial role of light quality in regulating plant growth is through leaf and stomatal development. Plants grown under $\mathrm{B}$ light supplemental to $\mathrm{R}$ light environment increased their SD resulting in greater photosynthetic capacity than those grown under B light-limited conditions (Hogewoning et al. 2010, Chang et al. 2016, Wang et al. 2016). In this study, all HR-RIL plants had similar shoot FM (Fig. 3E), but under $0 \mathrm{~B}$ and $8 \mathrm{~B}$ light treatments, SD values of HR-RIL were higher compared to other light treatment (Fig. 4C). Leaves grown under different light qualities involved changes in SD which could have contributed to differences in $g_{s}$ (Schoch et al. 1980, Hogewoning et al. 2010, Wang et al. 2016). Hogewoning et al. (2010) reported that $g_{s}$ and light-saturated $\mathrm{CO}_{2}$ assimilation rate $\left(P_{\max }\right)$ of cucumber (Cucumis sativus) significantly increased with increasing blue light percentage, resulting from increasing number of stomata on adaxial leaf surface. Although the total stomatal pore area only takes up about $3 \%$ of the leaf surface (Willmer and Fricker 1996), the exchange of $\mathrm{CO}_{2}$ correlates well with SD (Tanaka et al. 2013). This is because stomata are essential for the uptake of $\mathrm{CO}_{2}$, but not for $\mathrm{O}_{2}$. Thus, it is difficult to correlate $\mathrm{O}_{2}$ exchange with $\mathrm{SD}$ due to the concentration gradient between the atmosphere and inside 
the leaf for $\mathrm{O}_{2}$ is much greater than the gradient for $\mathrm{CO}_{2}$. However, in studies with lettuce, Wang et al. (2016) found that both $P_{\max }$ and $P_{\text {Nmax }}$ increased with increasing B/R light ratio until 1 , associated with increased $g_{s}$ and $\mathrm{SD}$, but there was no positive correlation between photosynthesis and shoot dry mass accumulation. It was reported that the SD of the abaxial and adaxial surfaces of rapeseed leaves (Brassicanapus L. cv. "Zhongshuang11) increased with increasing $\mathrm{B} / \mathrm{R}$ light ratio from 0 to $100 \%$ but with the highest $P_{\mathrm{Nmax}}$ under $25 \%$ of B light (Chang et al. 2016). In the present study, although we only measured $P_{\text {Nmax }}$, not $g_{s}$ and $P_{\max }$, our results supported the fact that an increase in SD does not always enhance photosynthesis, growth, and biomass accumulation (Kim et al. 2004, Chang et al. 2016, Wang et al. 2016). The effects of light quality on SD and the relationship between SD and $g_{s}$ and photosynthetic capacities are species-specific. Although SD was lower at 16B and 24B (Fig. 4C), 16B-light treatment under which plants had higher photosynthetic rate, could indeed be the most optimal light quality for growing HR-RIL despite the lack of distinctive shoot and root FMs, most probably due to the low quantity of supplementary LED lighting.

HS-RIL grown under SL and 24B were shorter (Fig. 3B). Since the leaf number, and shoot and root FMs were also similarly lower under SL than the rest of the light treatments, it could be due to these plants being exposed to lower light intensity as a result of the lack of supplementary lighting that resulted in smaller plants. As for HS-RIL at 24B (Fig. 3), lower shoot and root FMs could be due to the shorter plants. High blue light has been shown to reduce plant height (Islam et al. 2012, Nanya et al. 2012). It is interesting to note that the shoot/root ratio was greater after $8 \mathrm{~B}, 16 \mathrm{~B}$, and $24 \mathrm{~B}$ light treatments (Fig. 3I) for HS-RIL, despite the significantly lower shoot FM found at 24B, than at $8 \mathrm{~B}$. $8 \mathrm{~B}$ had significantly higher SD than that of $24 \mathrm{~B}$ (Fig. $3 D$ ), though the $P_{\text {Nmax }}$ was significantly lower at $8 \mathrm{~B}$ than $24 \mathrm{~B}$. Cumulatively, all these growth parameters (Fig. 3) demonstrate that HR-RIL grew better under $16 \mathrm{~B}$ whilst there is no distinctive evidence to demonstrate which light treatment was more optimal for HS-RIL. As such, it is noteworthy to recognize that they behaved differently under different qualities of supplementary light, despite their high genetic similarities. This result suggests that responses of HR-RIL and HS-RIL to supplementary LED light quality may also depend on other abiotic factors such as temperature, light intensity in the greenhouse. The responses of the two different lettuce RILs to these abiotic factors may be different.

It has been reported that B light effects on plant and photosynthetic performance could be due to its influence on photosynthetic pigments (Senger and Bauer 1987, López-Juez and Hughes 1995, Wang et al. 2016). However, in the present study, all photosynthetic pigments were highly similar across the light treatments, with the exception of lower total $\mathrm{Chl}$ content in both genotypes grown under SL, but higher $\mathrm{Chl} a / b$ ratios in HS-RIL grown under SL (Fig. 5). Wang et al. (2016) reported that lettuce grown under a mixture of $\mathrm{R}$ and $\mathrm{B}$ light or $\mathrm{B}$ light had a higher $\mathrm{Chl} a / b$ compared to red-light treatment (Wang et al. 2016). All LED-light treatments including sole $\mathrm{R}$ light resulted in higher total $\mathrm{Chl}$ content for both genotypes. B light deficiency that was adverse to $\mathrm{Chl}$ biosynthesis has been reported in wheat (Tripathy and Brown 1995), spinach (Matsuda et al. 2008), and cucumber seedling (Hogewoning 2010, Hernández and Kubota 2016) and Rosa $\times$ hybrida (Terfa et al. 2013). In the present study, it seemed that B light from the background sunlight was sufficient for the synthesis of Chl. It was also reported that B light can be absorbed either by $\mathrm{Chl}$ or by Car for the formation of 'sun-type' chloroplasts (López-Juez and Hughes 1995). However, all plants had similar Car content (Fig. 5E,F).

When measured at a PPFD of $605 \mu$ mol(photon) $\mathrm{m}^{-2} \mathrm{~s}^{-1}$, which was the saturated light intensity for ETR according to the light-response curves for all the plants (data not shown), $\mathrm{q}_{\mathrm{p}}$ and ETR values of HR-RIL grown under $16 \mathrm{~B}$ and $24 \mathrm{~B}$ were higher than those of plants grown under other lower level of $\mathrm{B}$ light or SL (Fig. 6A,E). These results indicate that plants under higher $\mathrm{B}$ light treatments utilized more light energy absorbed by Chl for photochemistry (Hemming 2011, Muneer et al. 2014, He et al. 2015b). Highest $\mathrm{q}_{\mathrm{p}}$ and ETR, with correspondingly the highest and lowest NPQ (Fig. 6C), were found, respectively, at $16 \mathrm{~B}$ and 24B light treatment for HR-RILs. Higher utilisation of light energy (i.e., higher $\mathrm{q}_{\mathrm{p}}$ and ETR) and higher capacity of heat dissipation (i.e., lower NPQ) when grown in the tropical greenhouse (He et al. 2001, He and Lee 2004) further confirmed that $16 \mathrm{~B}$ could be indeed the most optimal light quality for growing HR-RIL as mentioned earlier.

In a tropical greenhouse, plants cope with variation of light intensities daily. Excess absorbed light energy can be detrimental to PSII unless it is dissipated harmlessly in a process known as dynamic photoinhibition, which is a reversible down-regulation mechanism to reduce the light utilisation efficiency by diverting the excessive energy to the xanthophyll cycle so as to protect PSII reaction centers from photodamage (Demming-Adams and Adams III 1992, He et al. 2001, He and Lee 2004). The excess energy may cause damage to the PSII reaction center, leading to sustained photoinhibition or chronic photoinhibition (Barber 1995). Excessive light is usually associated with high temperature (He et al. 1996). Our previous study found that although dynamic photoinhibition measured by lower midday $\mathrm{Chl}$ fluorescence $\mathrm{F}_{\mathrm{v}} / \mathrm{F}_{\mathrm{m}}$ ratio occurred in both genotypes with less dynamic photoinhibition in HRRIL than in HS-RIL, chronic photoinhibition did not occur in either RIL (He et al. 2013). Similar results were also obtained in this study (data not shown). For HS-RIL, the highest $\mathrm{q}_{\mathrm{p}}$ and ETR and the lowest NQP were also found in plants grown under 24B. However, there were no significantly differences in $\mathrm{q}_{\mathrm{p}}$, ETR, and NPQ between plants grown under $16 \mathrm{~B}$ and SL. These results implied that the utilisation of light energy and capacity of heat 
dissipation were different between HR-RIL and HS-RIL under different supplementary LED lightings.

Conclusion: The present study suggested that 16B supplementary light treatment is optimal for HR-RIL. However, with the high shoot FM and shoot/root ratio in HS-RIL at $8 \mathrm{~B}$, this seemed to be the optimal light treatment. Based on further examination of its leaf growth and photosynthetic parameters, there seemed to be some evidence to support

\section{References}

Argyris J., Truco M.J., Ochoa O. et al.: Quantitative trait loci associated with seed and seedling traits in Lactuca. - Theor. Appl. Genet. 111: 1365-1376, 2005.

Ball J.T., Woodrow I.E., Berry, J.A.: A model predicting stomatal conductance and its contribution to the control of photosynthesis under different environmental conditions. - In: Biggins J. (ed.): Progress in Photosynthesis Research. Pp. 221224. Martinus-Nijhoff Publishers, Dordrecht 1987.

Barber J.: Molecular-basis of the vulnerability of photosystem-II to damage by light. - Aust. J. Plant Physiol. 22: 201-208, 1995.

Blaauw O.H., Blaauw-Jansen G.: The phototropic responses of Avena coleoptiles. - Acta Bot. Neerl. 19: 755-763, 1970.

Bula R.J., Morrow R.C., Tibbitts T.W. et al.: Light-emitting diodes as a radiation source for plants. - HortScience 26: 203205, 1991.

Chang S.X., Li C.X., Yao X.Y. et al.: Morphological, photosynthetic, and physiological responses of rapeseed leaf to different combinations of red and blue lights at the rosette stage. - Front. Plant Sci. 7: 1144, 2016.

Choong T.W., He J., Qin L., Dodd I.C.: Identifying heat-resistant recombinant inbred lines (RILs) of lettuce in the tropics: productivity and root phenotyping. - Acta Hortic. 1004: 173180, 2013.

Christophe A., Moulia B., Varlet-Grancher C.: Quantitative contributions of blue light and PAR to the photocontrol of plant morphogenesis in Trifolium repens (L.). - J. Exp. Bot. 57: 2379-2390, 2006.

Cope K.R., Bugbee B.: Spectral effects of three types of white light-emitting diodes on plant growth and development: Absolute versus relative amounts of blue light. - HortScience 48: 504-509, 2013.

Cosgrove D.J.: Rapid suppression of growth by blue light: Occurrence, time course, and general characteristics. - Plant Physiol. 67: 584-590, 1981.

Darko E., Heydarizadeh P., Schoefs B., Sabzalian M.R.: Photosynthesis under artificial light: the shift in primary and secondary metabolism. - Phil. T. Roy. Soc. B. 369: 20130243, 2014.

Demming-Adams B., Adams III W.W.: Photoprotection and other responses of plants to high light stress. - Annu. Rev. Plant Phys. 43: 599-626, 1992.

Douglas J.S.: Advanced Guide to Hydroponics. Pelham Books, London 1985.

Gifford R.M., Thorne J.H., Hitz W.D., Giaquinta R.T.: Crop productivity and photoassimilate partitioning. - Science $\mathbf{2 4}$ : 801-808, 1984.

Goins G.D., Yorio N.C., Sanwo M.M., Brown C.S.: Photomorphogenesis, photosynthesis, and seed yield of wheat plants grown under red light-emitting diodes (LEDs) with and without supplemental blue lighting. - J. Exp. Bot. 48: 1407-1413, 1997.

Goto E.: Plant production in a closed plant factory with artificial our initial hypothesis that HR-RIL and HS-RIL exhibited different response to supplemental light quality. The difference could be due to their different sensitivities to heat stress and dynamic photoinhibition in the tropical greenhouse. However, the impacts of LED quality on productivity of different Lactuca RILs grown in a tropical greenhouse need to be further investigated under different quantities of LED lightings.

lighting. - Acta Hortic. 956: 37-49, 2012.

Hanyu H., Shoji K.: Acceleration of growth in spinach by shortterm exposure to red and blue light at the beginning and at the end of the daily dark period. - Acta Hortic. 580: 145-150, 2002.

He J., Chee C.W., Goh C.J.: "Photoinhibition" of Heliconia under natural tropical conditions- Importance of leaf orientation for light interception and leaf temperature. - Plant Cell Environ. 19: 1238-1248, 1996.

He J., Cheok L., Qin L.: Nitrate accumulation, productivity and photosynthesis of temperate butter head lettuce under different nitrate availabilities and growth irradiances. - Open Hortic. J. 4: 17-24, 2011a

He J., Lee S.K., Dodd I.C.: Limitations to photosynthesis of lettuce grown under tropical conditions: alleviation by rootzone cooling. - J. Exp. Bot. 52: 1323-1330, 2001

He J., Lee S.K.: Photosynthetic utilization of radiant energy by temperate lettuce grown under natural tropical condition with manipulation of root-zone temperature. - Photosynthetica 42: 457-463, 2004.

He J., Lim L.I., Qin L.: Growth irradiance effects on productivity, photosynthesis, nitrate accumulation and assimilation of aeroponically grown Brassica alboglabra. - J. Plant Nutr. 38: 1022-1035, 2015a.

He J., Qin L., Chong E.L.C. et al.: Plant growth and photosynthetic characteristics of Mesembryanthemum crystallinum grown aeroponically under different blue- and red-LEDs. Front. Plant Sci. 8: 361, 2017.

He J., Qin L., Liu Y., Choong T.W.: Photosynthetic capacities and productivity of indoor hydroponically grown Brassica alboglabra Bailey under different light sources. - Am. J. Plant Sci. 6: 554-563, 2015 b.

He J., Seet L.T.L, Choong T.W. et al.: Photosynthesis and nitrogen metabolism of heat-resistant and heat-sensitive recombinant inbred lines (RILs) of lettuce under different rootzone temperatures. - Acta Hortic. 1004: 165-172, 2013.

He J., Tan B.H.G., Qin L.: Source-to-sink relationship between green leaves and green pseudobulbs of $\mathrm{C}_{3}$ orchid in regulation of photosynthesis. - Photosynthetica 49: 209-218, 2011b

Hemming S.: Use of natural and artificial light in horticulture Interaction of plant and technology. - Acta Hortic. 907: 25-36, 2011.

Hernández R., Kubota C.: Physiological responses of cucumber seedlings under different blue and red photon flux ratios using LEDs. - Environ. Exp. Bot. 121: 66-74, 2016.

Hoenecke M.E., Bula R.J., Tibbitts T.W.: Importance of blue photon levels for lettuce seedlings grown under red light emitting diodes. - HortScience 27: 427-430, 1992.

Hogewoning S.W., Trouwborst G., Maljaars H. et al.: Blue light dose-responses of leaf photosynthesis, morphology, and chemical composition of Cucumis sativus grown under 
different combinations of red and blue light. - J. Exp. Bot. 61: 3107-3117, 2010.

Islam M.A., Kuwar G., Clarke J.L. et al.: Artificial light from light emitting diodes (LEDs) with a high portion of blue light results in shorter poinsettias compared to high pressure sodium (HPS) lamps. - Sci. Hortic-Amsterdam 147: 136-143, 2012.

Johkan M., Shoji K., Goto F. et al.: Blue light-emitting diode light irradiation of seedlings improves seedling quality and growth after transplanting in red leaf lettuce. - HortScience 45: 1809-1814, 2010.

Jones D.S.: ASEAN and transboundary haze pollution in Southeast Asia. - Asia Eur. J. 4: 431-446, 2006.

Kim H.H., Goins G.D., Wheeler R.M., Sager J.C.: Stomatal conductance of lettuce grown under or exposed to different light quality. - Ann. Bot.-London 94: 691-697, 2004.

Koester R.P., Skoneczka J.A., Cary T.R. et al.: Historical gains in soybean (Glycine max Merr.) seed yield are driven by linear increases in light interception, energy conversion, and partitioning efficiencies. - J. Exp. Bot. 65: 3311-3321, 2014.

Lai C-H., He J.: Physiological performances of temperate vegetables with response to chronic and acute heat stress. Am. J. Plant Sci. 7: 2055-2071, 2016

Lee S.K.: Aeroponic system as a possible alternative for crop production in Singapore. - Commonw. Agric. Digest 3: 1-4. 1993.

Li H., Tang C., Xu Z.: The effects of different light qualities on rapeseed (Brassica napus L.) plantlet growth and morphogenesis. - Sci. Hortic.-Amsterdam 150: 117-124, 2013.

López-Juez E., Hughes M.J.G.: Effect of blue light and red light on the control of chloroplast acclimation of light-grown pea leaves to increased flounce rate. - Photochem. Photobiol. 61: 106-111, 1995.

Massa G.D., Kim H.H., Wheeler R.M., Mitchell C.A.: Plant productivity in response to LED lighting. - HortScience $\mathbf{4 3}$ : 1951-1956, 2008.

Matsuda R., Ohashi-Kaneko K., Fujiwara K., Kurata K: Effects of blue light deficiency on acclimation of light energy partitioning in PSII and $\mathrm{CO}_{2}$ assimilation capacity to high irradiance in spinach leaves. - Plant Cell Physiol. 49: 664-670, 2008.

Muneer S., Kim E.J., Park J.S., Lee J.H.: Influence of green, red and blue light emitting diodes on multiprotein complex proteins and photosynthetic activity under different light intensities in lettuce leaves (Lactuca sativa L.). - Int. J. Mol. Sci. 15: 4657-4670, 2014.

Nanya K., Ishigami Y., Hikosaka S., Goto E.: Effects of blue and red light on stem elongation and flowering of tomato seedlings. - Acta Hortic. 956: 261-266, 2012.

Nhut D.T., Takamura T., Watanabe H. et al.: Responses of strawberry plantlets cultured in vitro under super bright red and blue light-emitting diodes (LEDs). - Plant Cell Tiss. Org. 73: 43-52, 2003.

Nobre A.M., Karthik S., Liu H. et al.: On the impact of haze on the yield of photovoltaic systems in Singapore. - Renew. Energ. 89: 389-400, 2016.

Ooi A., Wong A., Ng T.K. et al.: Growth and development of Arabidopsis thaliana under single-wavelength red and blue laser light. - Sci. Rep. 6: 33885, 2016.
Sager J.C., McFarlane J.C.: Radiation. - In: Langhans R.W., Tibbitts T.W. (ed.): Plant Growth Chamber Handbook. Pp.129. Iowa State University Press, Ames 1997.

Senger H., Bauer B.: The influence of light quality on adaptation and function of the photosynthetic apparatus. - Photochem. Photobiol. 45: 939-946, 1987.

Schoch P.G, Zinsou C., Sibi M.: Dependence of the stomatal index on environmental factors differentiation in leaves of Vigna sinensis L. 1. Effect of light intensity. - J. Exp. Bot. 31: 1211-1216, 1980.

Schwartz A., Zeiger E.: Metabolic energy for stomatal opening: Roles of photophosphorylation and oxidative phosphorylation. - Planta 161: 129-136, 1984.

Stutte G.W., Edney S., Skerritt T.: Photoregulation of bioprotectant content of red leaf lettuce with light-emitting diodes. HortScience 44: 79-82, 2009.

Tanaka Y., Sugano S.S., Shimada T., Hara-Nishimura, I.: Enhancement of leaf photosynthetic capacity through increased stomatal density in Arabidopsis. - New Phytol. 198: 757-764, 2013.

Tay S., He J., Yam T.W.: Photosynthetic light utilization efficiency, water relations and leaf growth of C3 and CAM tropical orchids under natural conditions. - Am. J. Plant Sci. 6: 29492959, 2015.

Terfa M.T., Solhaug K.A., Gislerød H.R. et al.: A high proportion of blue light increases the photosynthesis capacity and leaf formation rate of Rosa $\times$ hybrida but does not affect time to flower opening. - Physiol. Plantarum 148: 146-159, 2013.

Tripathy B.C., Brown C.S.: Root-shoot interaction in the greening of wheat seedlings grown under red light. - Plant Physiol. 107: 407-411, 1995.

Wang J., Lu W., Tong Y., Yang, Q.: Leaf morphology, photosynthetic performance, chlorophyll fluorescence, stomatal development of lettuce (Lactuca sativa L.) exposed to different ratios of red light to blue light. - Front Plant Sci. 7: 250, 2016.

Watanabe H.: Light-controlled plant cultivation system in Japan - Development of a vegetable factory using LEDs as a light source for plants. - Acta Hortic. 907: 37-44, 2011.

Wellburn A.R.: The spectral determination of chlorophylls $a$ and $b$, as well as carotenoids, using various solvents with spectrophotometers of different resolution. - J. Plant Physiol. 144: 307-313, 1994

Weraduwage S.M., Chen J., Anozie F.C. et al.: The relationship between leaf area growth and biomass accumulation in Arabidopsis thaliana. - Front. Plant Sci. 6: 167, 2015.

Willmer C., Fricker M.: Stomata. Chapman \& Hall, London 1996.

Yeh N., Chung J.: High-brightness LEDs - Energy efficient lighting sources and their potential in indoor plant cultivation. - Renew. Sust. Energ. Rev. 13: 2175-2180, 2009.

Yorio N.C., Goins G.D., Kagie H.R. et al.: Improving spinach, radish, and lettuce growth under red light-emitting diodes (LEDs) with blue light supplementation. - HortScience 36: 380-383, 2001. 